\title{
Basin and crustal velocity structure models for the simulation of strong ground motions in the Kinki area, Japan
}

\author{
Tomotaka Iwata • Takao Kagawa • \\ Anatoly Petukhin · Yoshihiro Ohnishi
}

Received: 19 April 2007 / Accepted: 10 December 2007 / Published online: 19 January 2008

(C) The Author(s) 2007

\begin{abstract}
We constructed a prototype of the basin and crustal structure model for the Kinki area, southwest of Japan, for the simulation of strong ground motions of hypothetical crustal and subduction earthquakes. We collected results of the deep seismic velocity profiles obtained by the reflection experiments and seismic imaging results, which were conducted in the Kinki area. The obtained profiles give underground velocity structures of the crust, from the surface to the subducting slab. We also gather the basin velocity structure information of the Osaka, Kyoto, Nara, and Ohmi basins. To examine the applicability of the constructed velocity structure model to the ground motion simulation, we simulated waveforms of an intermediate size event occurred near the source area of the hypothetical subduction earthquakes. Simulated ground motions using the basin and crustal velocity structure model are fairly well reproducing the observations at most of stations, and the constructed basin and crustal velocity struc-
\end{abstract}

T. Iwata $(\bowtie)$

Disaster Prevention Research Institute, Kyoto University, Gokasho,

Uji, Kyoto 611-0011, Japan

e-mail: iwata@egmdpri01.dpri.kyoto-u.ac.jp

T. Kagawa $\cdot$ A. Petukhin $\cdot$ Y. Ohnishi

Geo-Research Institute,

Osaka, Japan ture model is applicable for the long-period ground motion simulations.

Keywords Long-period ground motion . Ground motion prediction .

Basin and crustal velocity structure model

\section{Introduction}

Ground motion simulations and predictions based on the source model and the underground velocity structure model are quite important for understanding the characteristics of strong ground motions and the related earthquake disasters. Since the 1994 Northridge, USA and 1995 Kobe, Japan earthquakes, strong motion simulations using a heterogeneous source and realistic 3D underground velocity structure models became successful and quite popular in the research field of applied seismology and earthquake engineering.

In Japan, the Kinki area has a high seismic hazard potential. Based on the long-term evaluation of earthquake occurrence, the Headquarters for Earthquake Research Promotion (HERP), the Ministry of Education, Culture, Sports, Science, and Technology (MEXT), Japan, reported that the occurrence potentials of the next Nankai and Tonankai earthquakes are high: approximately $50 \%-70 \%$ within the next 30 years beginning from 2007 (HERP 2007). It is also predicted that several inland crustal earthquakes occurred in the 
decades before the last (Showa) Tonankai (1944) and Nankai (1946) earthquakes in the Kinki area (Hori and Oike 1996). Therefore, there is a high probability that in addition, M7-class inland crustal earthquakes will strike the Kinki area before the next Nankai and Tonankai earthquakes.

Long-period ground motions from M8-class events have often rocked facilities on basin or sedimentary sites located $200-300 \mathrm{~km}$ away from the source region, e.g., the well-known damage in Mexico City during the 1985 Michoacan earthquake or in Tomakomai, Hokkaido, Japan, during the 2003 Tokachi-Oki earthquake. In the case of Tomakomai, the long-period ground motions, generated from the source and then amplified and elongated in the Yufutsu basin, damaged oil storage tanks (Koketsu et al. 2005). These generation and propagation characteristics of long-period ground motions were directly monitored by the K-NET (Kinoshita 1998) strong motion array. Aoi et al. (2001) successfully simulated long-period ground motions by seismic waveform modeling using the source model and underground velocity structure model.

The Osaka sedimentary basin is located approximately $150 \mathrm{~km}$ away from the source regions of the hypothetical Tonankai and Nankai earthquakes, and the same situation would occur in that the modern megacities of Osaka and Kobe, located in this sedimentary basin, would definitely be shaken by disastrous long-period ground motions from M8-class subduction earthquakes. At the moment of the last Tonankai and Nankai events (the 1944 Showa Tonankai and 1946 Nankai), there were very few long-period structures in the sedimentary basin, whereas now, the megacities comprise a large number of skyscrapers, oil storage tanks, long-span bridges, etc. For earthquake disaster reduction, reliable strong motion predictions are required at the sites.

Velocity structure models have already been constructed by several organizations and research groups. These are mainly constructed for evaluating the ground shaking level relative to the earthquake disasters in general houses or for mapping the seismic intensity. Here, our objective is the simulation of long-period ground motions. We constructed the sedimentary basin and crustal velocity structure model in the Kinki area by compiling many available seismic survey results and local basin models. We demonstrate the applicability of this velocity structure model for strong motion evaluations through simulations of the ground motions observed by the dense strong motion network in the Kinki area.

\section{Construction of basin and crustal velocity structure model}

\subsection{Crustal velocity structure model}

The general principle of crustal velocity modeling is to build a model from several layers with constant values of velocity, density, and quality factor $Q$ within each layer. The model interfaces between the layers are 3D. We used the spline interpolation method (e.g., Koketsu and Higashi 1992) to represent the interface depths, following the approach developed earlier for the basin model described below. Figure 1 shows the model area of the crustal velocity structure that includes the source area of the Nankai and Tonankai earthquakes. The model covers most of Western Japan between $130-138^{\circ} \mathrm{E}$ and $31-36^{\circ} \mathrm{N}$.

Figure 2 shows a schematic cross-section of the crustal velocity structure model that includes the subducting Philippine Sea slab in the Kinki area. It reflects the main principles of velocity modeling, developed by Petukhin et al. (2003) and Iwata et al. (2006). They are: (1) intensive use of the OBS velocity models in offshore areas for the accretion prism, or the sedimentary wedge, and oceanic crust

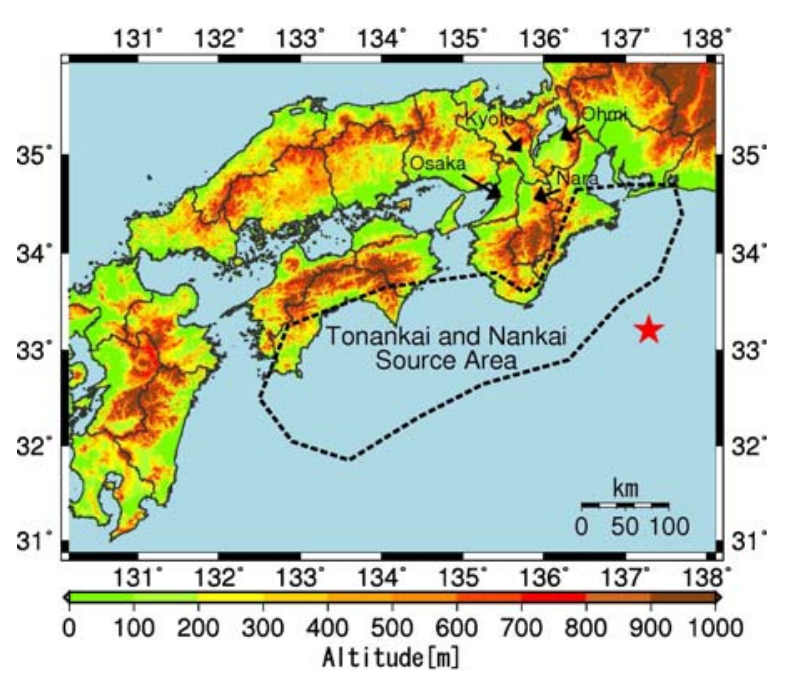

Fig. 1 Map of target area. The star indicates the epicenter of the target event for waveform simulation in this study $\left(M_{J} 6.4\right.$, 2004/9/7) 
Fig. 2 Schematic cross section of the crustal velocity structure model. Assumed $P$-wave velocity for each layer is also shown (Iwata et al. 2006)

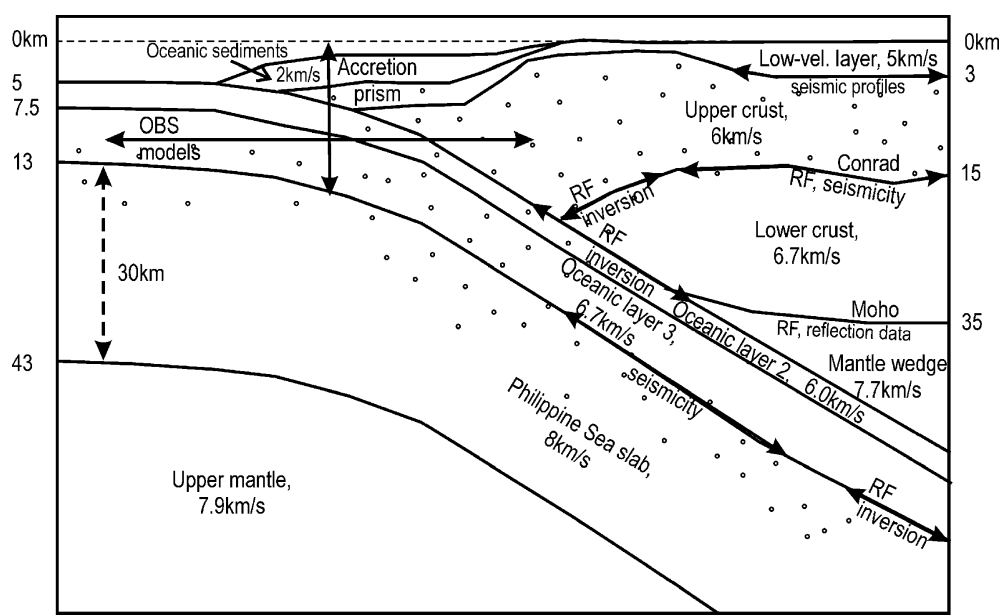

modeling; (2) employing seismicity data for tracing the seismogenic slab and seismogenic upper crust; (3) intensive use of the receiver function inversion results for tracing Moho, and Conrad and slab in the aseismic areas; (4) employing deep seismic profiling results for inland areas whenever possible; and (5) employing $1 \mathrm{D}$ velocity models used for the hypocenter locations and generalized seismic tomography results for the remaining areas not covered by the data.

The velocity model was constructed from nine constant velocity layers: (1) oceanic sedimentary layer, (2) surface low-velocity layer, (3) upper crust, (4) lower crust, (5) mantle wedge, (6) oceanic crust layer 2, (7) oceanic crust layer 3, (8) slab, and (9)

Table 1 References to the data used to construct the model

\begin{tabular}{lll}
\hline Interface & $\begin{array}{l}\text { Type of data used } \\
\text { (in the order of preference) }\end{array}$ & References \\
\hline
\end{tabular}

Depth of the oceanic OBS seismic profiles

sedimentary layer

Depth of the surface low-velocity layer Conrad

Moho

Top of the oceanic crust

Top of oceanic layer 3

Upper boundary of slab
Seismic profiles

Seismic profiles; lower limit of the crust seismicity; receiver function inversion

Seismic profiles; receiver function inversion; travel time inversion

1. OBS seismic profiles; receiver function inversion; upper boundary of slab minus $7 \mathrm{~km}$

OBS seismic profiles; upper boundary of slab minus 5-6 km

OBS seismic profiles; upper limit of the subduction seismicity; receiver function inversion

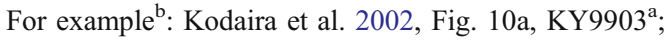
Nakanishi et al. 2002, Fig. 10, KR9806 ${ }^{\text {a }}$, ERI database, ERI94NS, ERI94EW, ERI95NS, ERI95EW ${ }^{\text {a }}$ JAMSTEC database, KY04-01: NT0402, NT0403

For example ${ }^{\mathrm{b}}$ : Ito et al. 2005; Shingu-Maizuru, Keihoku-Seidan; OBS models above

For example $^{\text {b: }}$ Ito et al. 2005, Shingu-Maizuru, Keihoku-Seidan; Nakanishi et al. 2002, Fig. 10, KR9806 ${ }^{\text {a }}$; Also: Ito 1999, Fig. 3; Yamauchi et al. 2003, Fig. 4

For example $^{\text {b: }}$ Ito et al. 2005, Shingu-Maizuru,

Keihoku-Seidan; Kodaira et al. 2002, Fig. 10a, KY9903 ${ }^{\text {; }}$; Also: Shiomi et al. 2004b, Fig. 2; Yamauchi et al. 2003,

Fig. 4; Salah and Zhao 2004, Fig. 12

OBS models above; Shiomi et al. 2004a

OBS models above

OBS models above; Miyoshi and Ishibashi 2004, Fig. 7; Baba 2002; Shiomi et al. 2004a, b

\footnotetext{
${ }^{\mathrm{a}}$ Indexes of the profiles are according to the JAMSTEC nomenclature.

${ }^{\mathrm{b}}$ The complete list of the seismic profiling results used in this study is too long to be referenced here; we only refer to the most important examples in the nearest vicinity to the target basins and the Kii peninsula.
} 
Fig. 3 Distributions of the control points for the Moho interface (a) and the bottom interface of the oceanic sedimentary layer (b) a

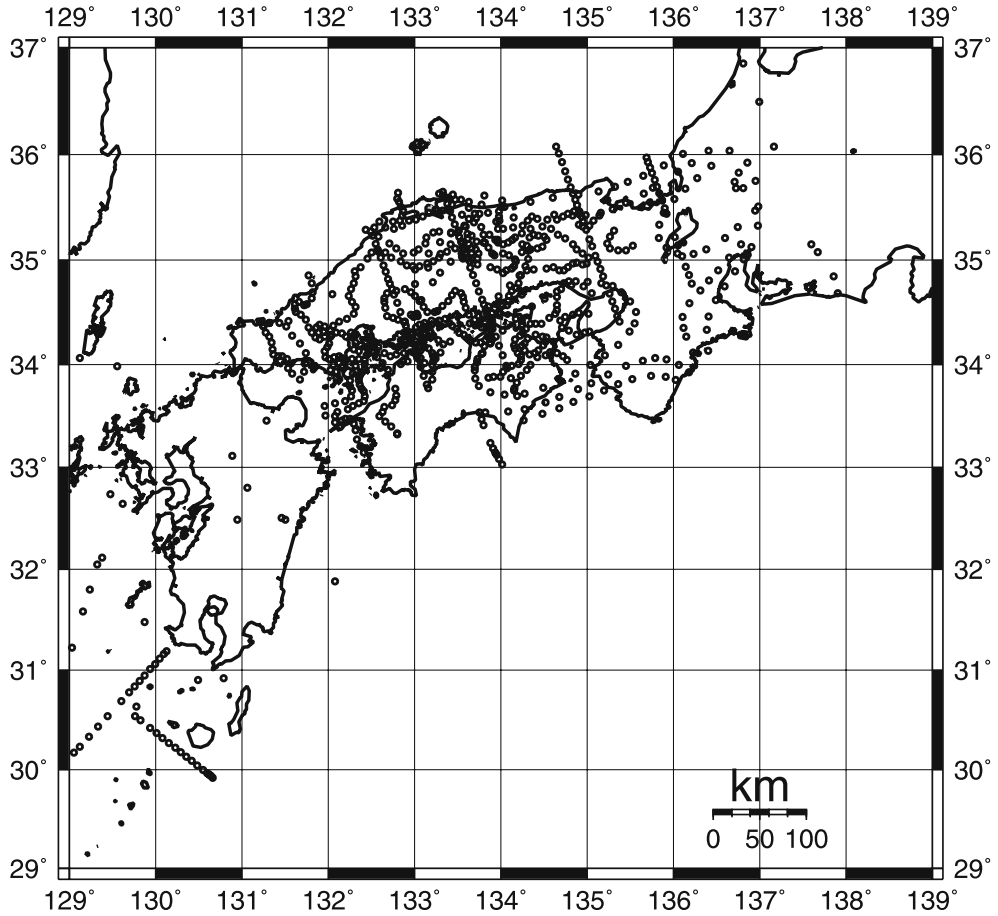

b

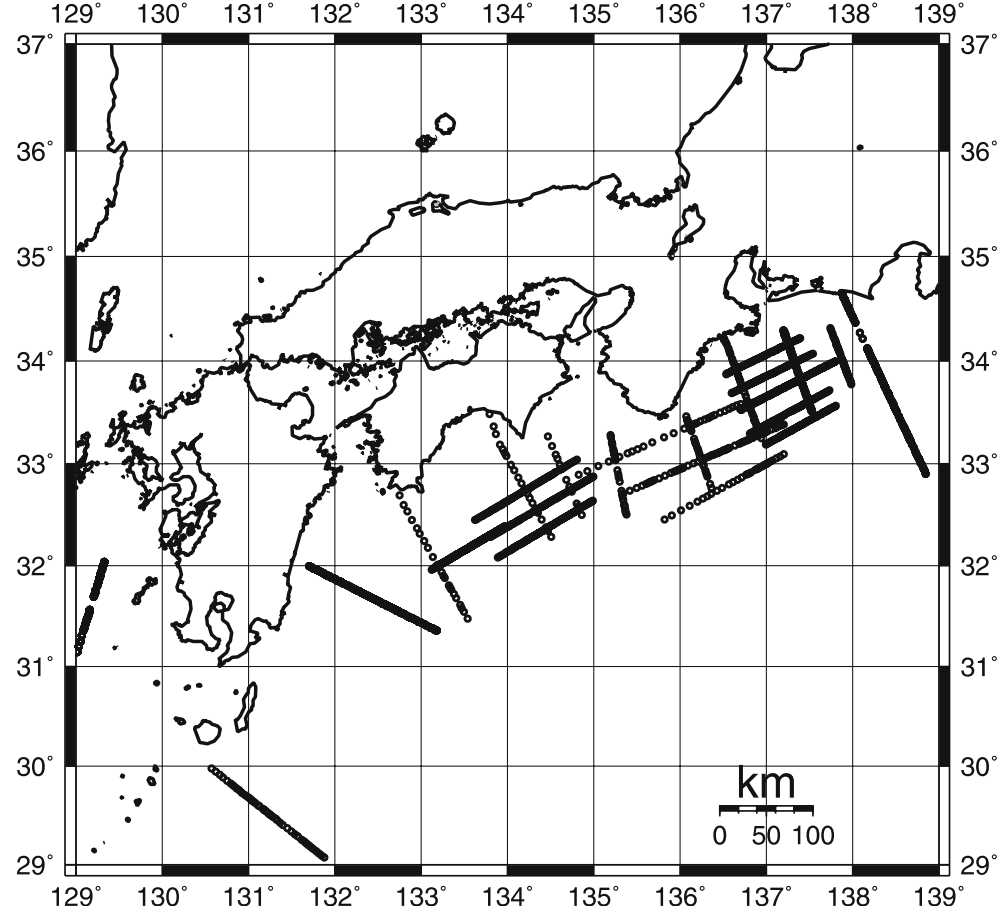


upper mantle. Their boundaries are the next interfaces: (1) ground surface (or ocean bottom), (2) lower interface of the oceanic sedimentary layer, (3) lower interface of the surface low-velocity layer, (4) Conrad interface, (5) Moho interface, (6) top boundary of the oceanic layer 2 (oceanic upper crust), (7) top boundary of the oceanic crust layer 3 (oceanic lower crust), (8) upper boundary of the slab (oceanic Moho), (9) bottom boundary of the slab (see Fig. 1). The accretion prism corresponds to the oceanic sedimentary layer and surface low-velocity layer beneath the oceanic sedimentary layer area in our model.

In 2004, a deep seismic exploration experiment crossing the Kinki area was conducted by a project for the regional characterization of the crust in metropolitan areas for the prediction of strong ground motion (Ito et al. 2005). Before this experiment, the crustal structure and subducting slab structure were studied by $P$-wave exploration surveys (e.g., Kodaira et al. 2002, Nakanishi et al. 1998, 2002) and using the earthquake records by the receiver function method (e.g., Yamauchi et al. 2003). We also refer to seismic cross-section databases [JAMSTEC (Japan Agency of Marine-Earth Science and Technology), 2006; ERI (Earthquake Research Institute, University of Tokyo), 2006]. The velocity structure models obtained from the OBS (Ocean Bottom Seismometer) measurements were also used. Table 1 compiles the references used for the construction of each model interface.

We read the interface depth from the seismic cross sections and create the interfaces in the velocity model by the smooth curvatures from interpolation. The distributions of the controlled points for the Moho interface and the bottom interface of the oceanic sedimentary layer are shown in Fig. 3 as an example.

Because the velocity structure models are mainly obtained for $P$-waves, we refined them and assigned the $S$-wave velocity values for each layer. Table 2 shows the $P$ - and $S$-wave velocity values, density, and $Q$ values assigned to each layer. They are estimated by generalizing the following: (1) the $1 \mathrm{D}$ velocity models used for locating the hypocenter in the studied area, (2) the seismic tomography results (e.g. Salah and Zhao 2003a), and (3) the OBS velocity models. The $Q$-structure is similar to that of Salah and Zhao 2003b), and is slightly modified according to the results of Petukhin et al. 2003, 2007. In the subducting area, the accretion prism or the sedimentary wedge is observed in the cross sections of the exploration surveys (e.g., Kodaira et al. 2002, Nakanishi et al. 1998, 2002). The thickness of these sediments appears to be several kilometers, and this strongly affects the results of ground motion simulations for subduction events (e.g. Yamada and Iwata 2005). Figure 4 shows the depth contour maps of the Moho interface and the bottom interface of the oceanic sedimentary in the studied area that includes the source region of the hypothetical Tonankai and Nankai earthquakes.

\subsection{Basin velocity model}

We used precompiled models for major sedimentary basins in the Kinki area, i.e., Osaka, Kyoto, Nara, and Ohmi (Shiga) basins. In particular, the Osaka sedimentary basin model had been well developed by Kagawa et al. (2004a, b). They compiled the seismic reflection and refraction survey results, borehole information, $S$-wave velocity structure of the sediments by microtremor array measurements, and the estimated basin depth by microtremor $\mathrm{H} / \mathrm{V}$ measurements. They assumed a three-layer velocity model in the sediments. Each layer has uniform $P$ - and $S$-wave velocities and the interface depths between layers are proportional to the basement depth. The basement interface of the sediments is explained by the B-spline function (e.g., Koketsu and Higashi 1992). In this model, it is easy to add newly obtained underground structure information. Here, we refined the model by adding the newly obtained basement depth informa-

Table 2 Velocity structures of the crustal model

\begin{tabular}{|c|c|c|c|c|}
\hline Layer & $\mathrm{Vp}, \mathrm{m} / \mathrm{s}$ & $\mathrm{Vs}, \mathrm{m} / \mathrm{s}$ & $\begin{array}{l}\text { Density, } \\
\mathrm{kg} / \mathrm{m}^{3}\end{array}$ & $Q$ value \\
\hline $\begin{array}{l}\text { Oceanic sedimentary } \\
\text { layer }\end{array}$ & 2,000 & 1,000 & 2,000 & 200 \\
\hline $\begin{array}{l}\text { Surface low-velocity } \\
\text { layer }\end{array}$ & 5,000 & 2,700 & 2,740 & 500 \\
\hline Upper crust & 6,000 & 3,450 & 2,800 & 1000 \\
\hline Lower crust & 6,700 & 3,900 & 2,900 & 500 \\
\hline Mantle wedge & 7,700 & 4,450 & 3,100 & 1000 \\
\hline Oceanic crust layer 2 & 6,000 & 3,450 & 2,700 & 500 \\
\hline Oceanic crust layer 3 & 6,700 & 3,900 & 2,800 & 500 \\
\hline Slab & 8,000 & 4,630 & 3,220 & 1000 \\
\hline Upper mantle & 7,900 & 4,570 & 3,100 & 1000 \\
\hline
\end{tabular}

Layers are corresponding to those shown in Fig. 2. 
tion from the seismic exploration surveys mentioned above (Ito et al. 2005). We also conducted additional microtremor array measurements in the area south of the Osaka basin and $\mathrm{H} / \mathrm{V}$ microtremor measurements at the north edge of the Osaka basin; thus far, little exploration information has been obtained from these areas. Figure 5 compares the control point distributions along with the basement depth contour of the Osaka basin, from Kagawa et al. (2004a, b) and from this study.
With regard to the Kyoto and Ohmi basins, local governments have modeled the sedimentary basin velocity structures for evaluating the earthquake damage that would result in an earthquake scenario (Kyoto City 2004; Kagawa et al. 2006; Table 3). These models are also represented by a stack of uniform velocity layers. Kagawa et al. (2005) modeled the Nara basin as a test case of a basin structure construction having relatively poor geophysical information. We conducted microtremor $\mathrm{H} / \mathrm{V}$ measurements in the Nara basin in order to
Fig. 4 Depth contour maps of the Moho interface (a) and the bottom interface of the oceanic sedimentary layer (b)
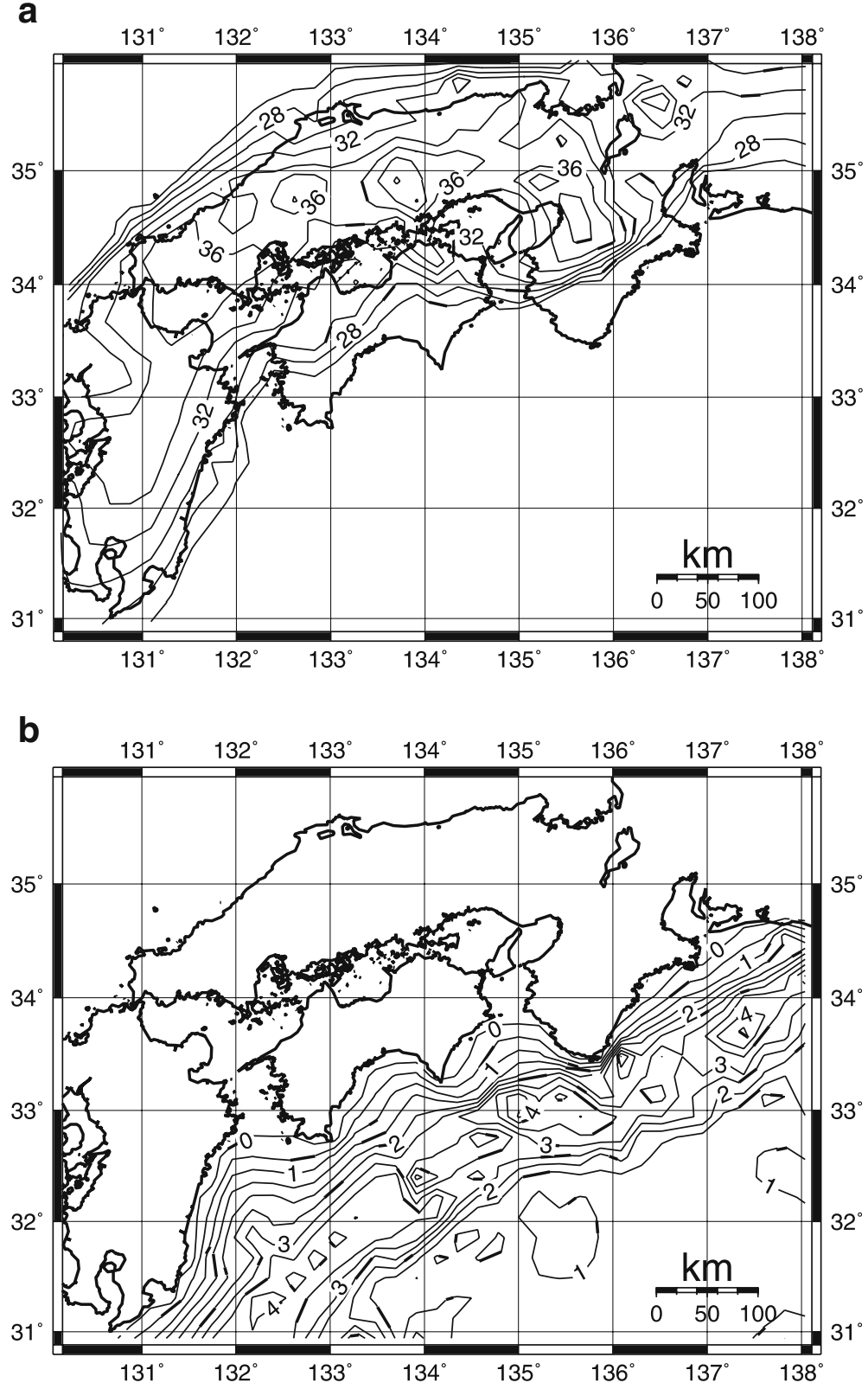

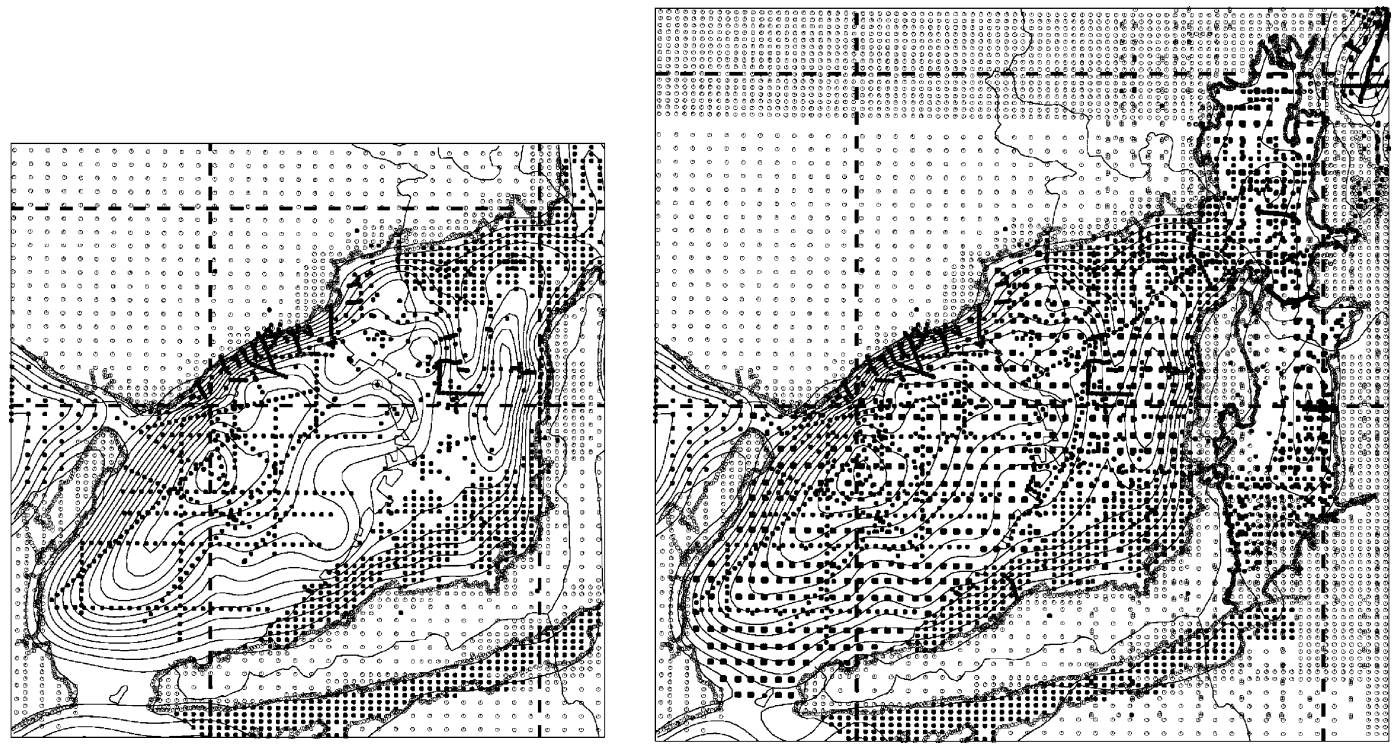

Fig. 5 Comparison of the control point distributions of Kagawa et al. (2004a, b) and this study for the Osaka basin. Basement depth contours are superimposed on each figure

add the basin depth information. Although the local governments modeled the basins only in the areas of their prefectures, it is natural to connect the Osaka, Kyoto, and Nara basins geologically. We connected the Kyoto basin to the northeast of the Osaka basin and the Nara basin to the south of the Kyoto basin. We assumed that the $S$-wave velocities in the sediments change gradually between the basins because the defined $S$-wave velocities in the sediments of different basins are slightly different. In Fig. 6, we show the basement depth of the Osaka, Kyoto, Nara, and Ohmi whole basin models constructed here. We also show a bird's-eye view map of the basement depth of the Osaka, Kyoto, and Nara basins (Fig. 7). We inserted this basin velocity structure model into the crustal velocity structure model mentioned above, as shown in Fig. 6.

\section{Estimation of the applicability of the basin and crustal structure models by waveform modeling}

To construct the velocity structure model, we extensively interpolated, extrapolated, and averaged the medium parameters by employing various assumptions; therefore, the resulting velocity structure model should be examined for its applicability to ground motion simulation. After the 1995 Kobe earthquake, the government increased the number of strong motion networks, e.g., the abundant data of the K-NET and KiK-net collected by the NIED (National Research Institute for Earth Science and Disaster Prevention) became available. We also used the strong velocity seismometer network operated by CEORKA (Committee of Earthquake Observation and Research in the Kansai Area) and ERI. This

Table 3 Velocity structures of the basin models

\begin{tabular}{llllll}
\hline Basin & Layer & $\mathrm{Vp}, \mathrm{m} / \mathrm{s}$ & $\mathrm{Vs}, \mathrm{m} / \mathrm{s}$ & Density, $\mathrm{kg} / \mathrm{m}^{3}$ & $Q$ value \\
\hline Osaka & 1 & 1,600 & 350 & 1,700 & 175 \\
& 2 & 1,800 & 550 & 1,800 & 275 \\
& 3 & 2,500 & 1,000 & 2,100 & 500 \\
& 4 & 5,000 & 2,700 & 2,740 & 500 \\
Kyoto & 1 & 1,690 & 390 & 1,920 & 195 \\
& 2 & 1,960 & 610 & 2,110 & 305 \\
& 3 & 2,270 & 890 & 2,200 & 445 \\
& 4 & 5,000 & 2,700 & 2,740 & 500 \\
Nara & 1 & 1,600 & 350 & 1,700 & 175 \\
& 2 & 1,800 & 550 & 1,800 & 275 \\
& 3 & 2,300 & 800 & 2,100 & 400 \\
& 4 & 5,000 & 2,700 & 2,740 & 500 \\
Ohmi & 1 & 1,800 & 390 & 1,810 & 195 \\
& 2 & 2,000 & 620 & 1,940 & 310 \\
& 3 & 2,500 & 950 & 2,040 & 475 \\
& 4 & 5,000 & 2,700 & 2,740 & 500 \\
\hline
\end{tabular}

The parameters of neighboring basins are smoothly connected through a matching region 
Fig. 6 Basement depth contour map of the Osaka, Kyoto, Nara, and Ohmi whole basin models $134.8^{\circ} 135^{\circ} 135.2^{\circ} 135.4^{\circ} 135.6^{\circ} 135.8^{\circ} 136^{\circ} 136.2^{\circ} 136.4^{\circ}$

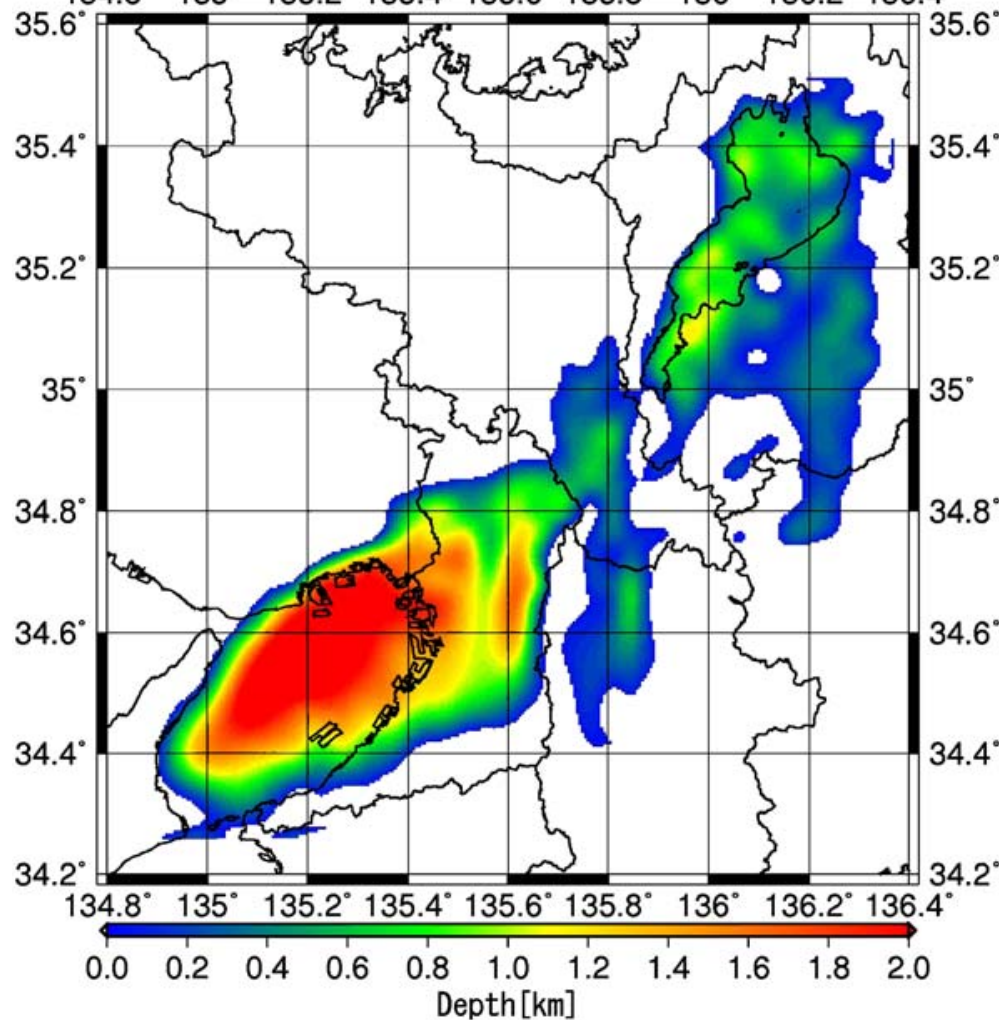

data enables the examination of the applicability of this type of velocity structure model for ground motion evaluation by simulating the ground motion records for intermediate size events. Kagawa et al. (2004a, b) performed waveform modeling at stations within the Osaka basin for small events occurring beneath the Osaka basin and showed the validity of

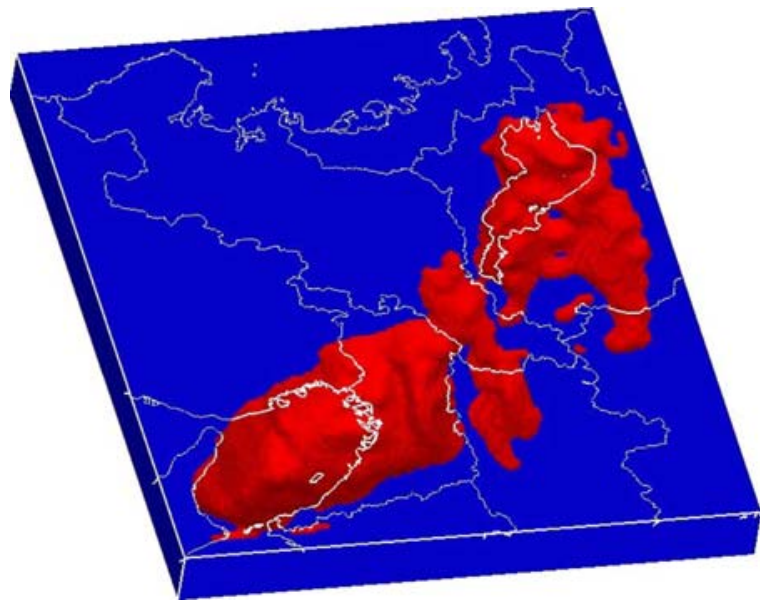

Fig. 7 Bird's-eye view of the basement depth of the basins the Osaka basin structure model at around $2 \mathrm{~s}$. Because of the low $\mathrm{S} / \mathrm{N}$ ratio for local M5-class events, ground motions could not be observed for longer than $2 \mathrm{~s}$. Here, to observe longer ground motions, we performed waveform modeling for the $M_{\mathrm{J}} 6.5$ largest aftershock of the 2004 Kii-HantoNanto-Oki earthquake $\left(M_{\mathrm{J}} 7.4\right)$. This earthquake occurred near the source region of the hypothetical Tonankai earthquake.

For simulations, we employed the 3D finite difference method (Graves 1996) with a nonuniform grid size (Pitarka 1999). The total calculation area is approximately NS: $310 \mathrm{~km}$, EW: $295 \mathrm{~km}$, and UD: $35 \mathrm{~km}$. The smallest finite difference grid was designed to be $100 \mathrm{~m}$. The minimum $S$-wave velocity was assumed to be $350 \mathrm{~m} / \mathrm{s}$. The shortest target period in the simulations was approximately $3 \mathrm{~s}$, that is decided by the grid size and S-wave velocity of the

Fig. 8 Comparisons of the simulated waveforms with the observed velocity waveforms: (a) for stations outside the basins; (b) for stations within the basins, except CEOHSD, which is outside the basin; and (c) station distribution 
a

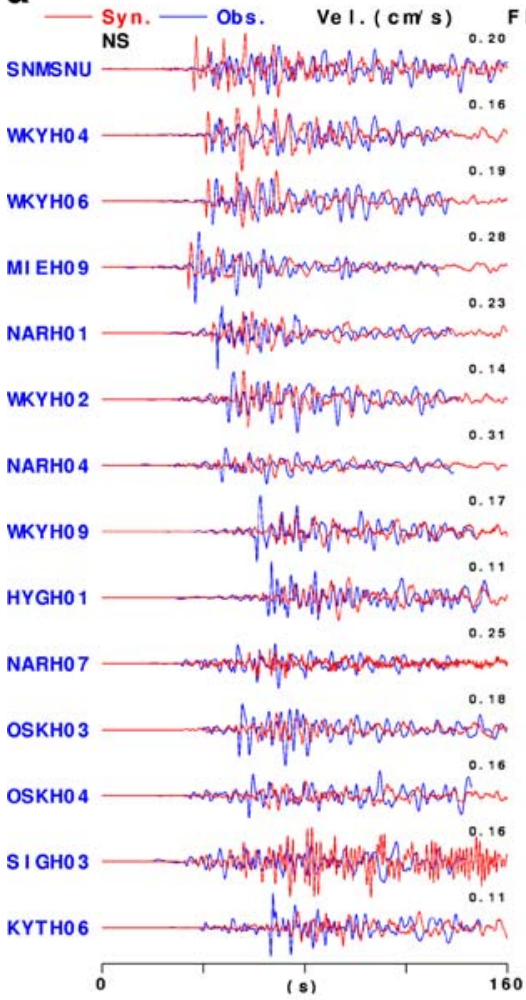

t. $0.10-0.30(\mathrm{~Hz})$

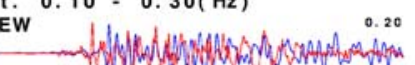

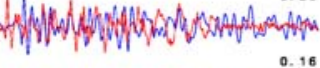

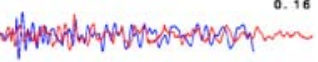

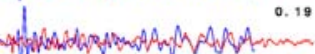
0.28

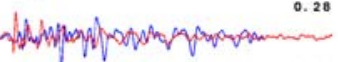

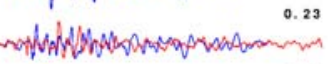
0.14

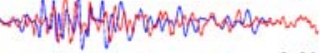

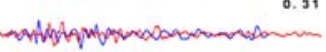

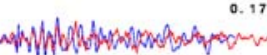

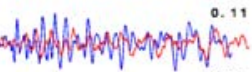

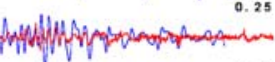
0.18

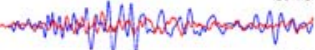

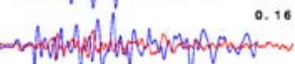

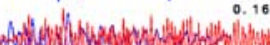

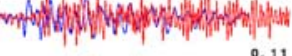

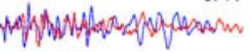

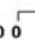

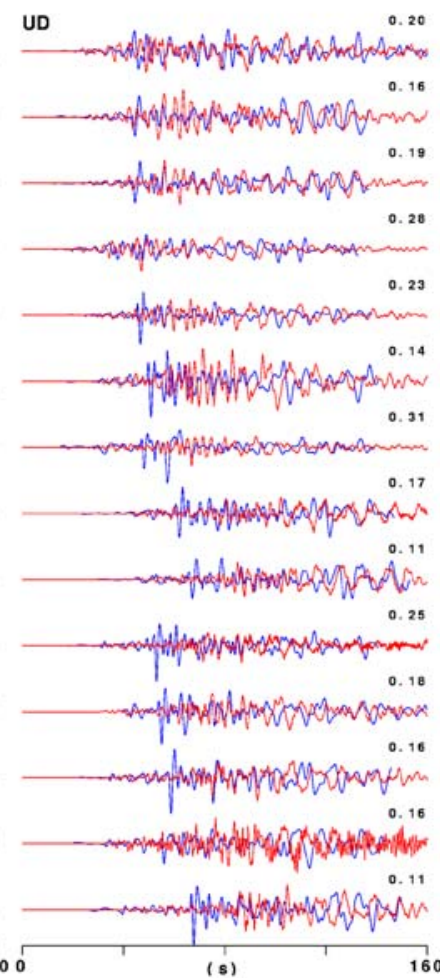

(s)
EW

$0.10-0.30(\mathrm{~Hz}$

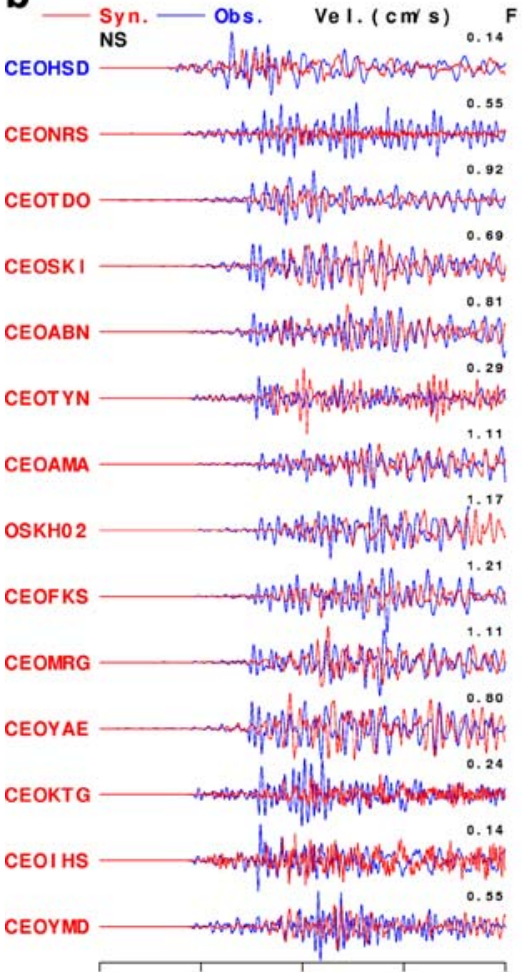

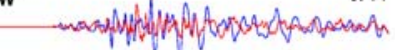

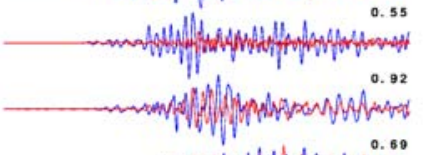

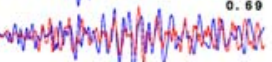

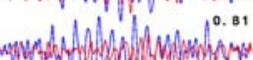

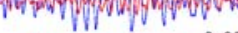

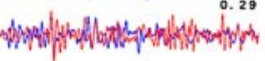

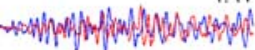

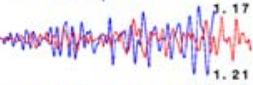

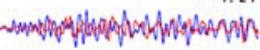

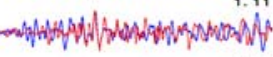

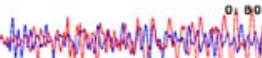
0.24

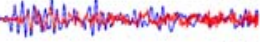
and How

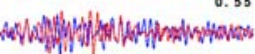




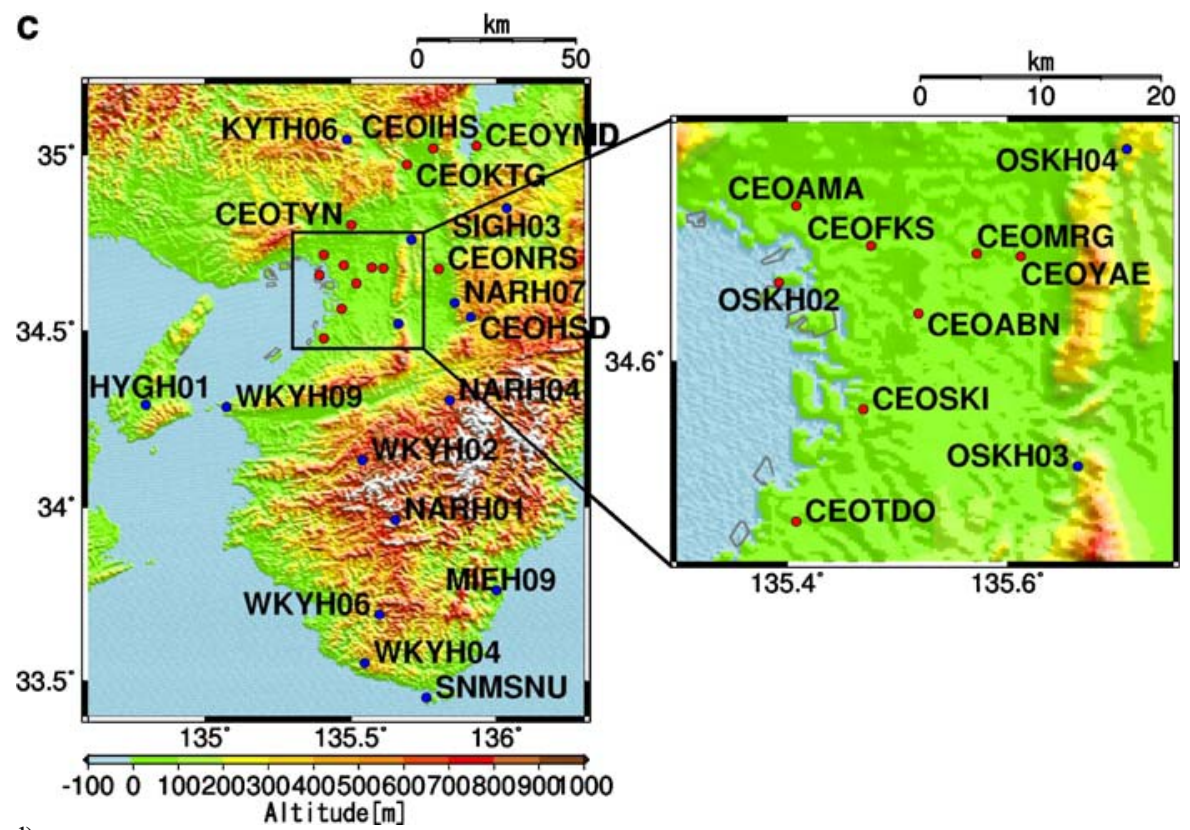

Fig. 8 (continued)

oceanic sedimentary layer. The calculation used 30000 time steps with a time interval of $0.008 \mathrm{~s}$.

The simulated waveforms as well as the observed velocity waveforms are shown in Fig. 8. Comparisons of the waveforms for stations outside and within the basins are shown in Fig. 8a and b, respectively. The station distribution is shown in Fig. 8c. The velocity waveforms are band-pass-filtered between 0.10 and $0.30 \mathrm{~Hz}$. At the SMN site, the rock site closest to the hypocenter, ground motions having both long period and long duration are observed. This is due to the effects of the oceanic sedimentary layer along the Nankai trough, which has already been pointed out by Yamada and Iwata (2003). The synthesized ground motions at SNMSNU roughly reproduce this long duration effect due to the additional low-velocity layer in our velocity structure model, corresponding to the oceanic sedimentary layer. Synthetic ground motions at the stations outside the basin reproduce the overall features of the observed ground motions. Synthetic ground motions at most stations within the basin exhibit both large amplifications of the $S$-wave
Fig. 9 Comparison of the maximum ground velocities of the horizontal components between the observation (blue) and the synthetics (red)

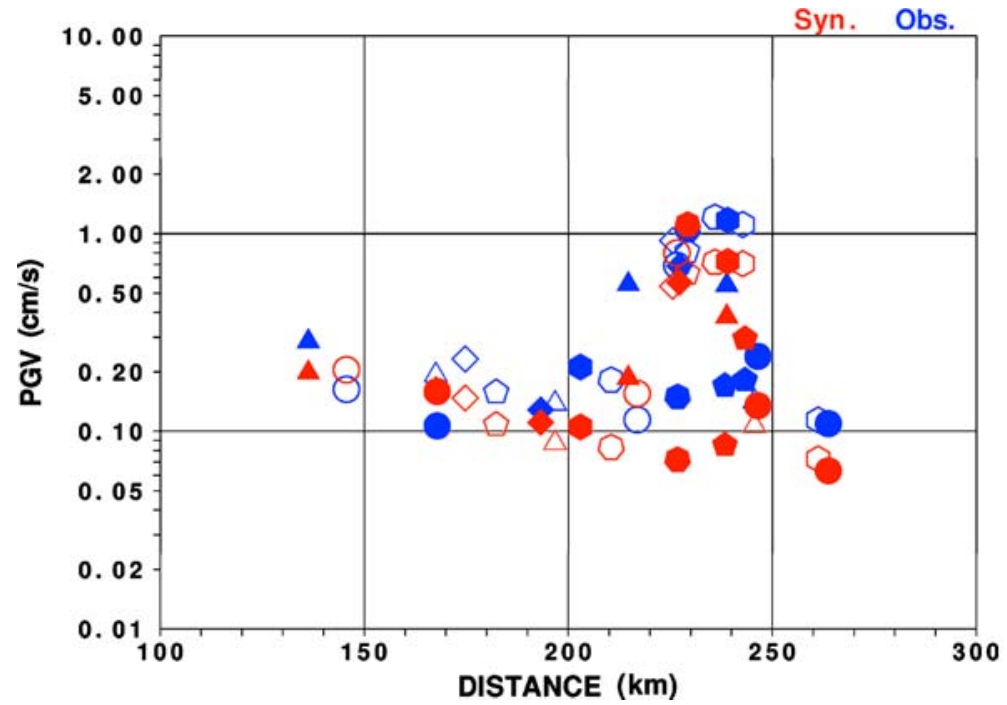


portions and long durations that are visible in the observations. However, at several stations, e.g., CEONRS in the Nara basin, CEOKTG at the edge of the Kyoto basin, and CEOYMD in the Ohmi basin, the synthesized ground motions do not suitably reproduce the observations. For example, the predominant period of the synthesized ground motions at the CEONRS site is different from the observed predominant period. For more reliable ground motion simulations, it is necessary to improve the velocity model. Figure 9 shows a comparison of the maximum ground velocities of the horizontal components between the observations and the synthetic motions. The observed maximum ground velocity values are well reproduced by the synthetics within a factor of 2 for all stations. This implies that the general characteristics of wave propagation are well simulated by the constructed velocity model.

\section{Concluding remarks}

We have constructed a prototype of the basin and crustal structure model in the Kinki area, southwest of Japan, for the strong ground motion prediction of the hypothetical crustal and subduction earthquakes. For constructing the crustal velocity structure model, we compiled the results of seismic explorations. With regard to the basin velocity models, we used the previous basin structure models as well as the new seismic exploration survey results, microtremor array measurements, and borehole logging data. The constructed basin and crustal velocity model has been examined by the waveform modeling of real seismic records. The reproduction of waveforms in the Osaka basin is suitable; however, that in the Nara, Kyoto, and Ohmi basins is unsuitable. This is because the data are still insufficient to construct basin velocity models for the Nara and Ohmi basins. Thus far, this prototype basin and crustal velocity structure model can reproduce the observed ground motions, as shown in Figs. 8 and 9. It is necessary to further improve the model using such observed waveforms to obtain results that are more appropriate results.

Acknowledgement We used the data of the CEORKA, K-NET, and KiK-net strong motion networks, ERI strong motion station data, and seismic exploration results from the JAMSTEC and ERI databases. Some figures are drawn using the GMT (Wassel and Smith 1998). This study is supported by the "Regional character- ization of the crust in metropolitan areas for prediction of strong ground motion" project 2002-2006 by MEXT, Japan, and Grantin-Aid for Scientific Research (B) (No.18310123, P.I.:T. Iwata).

Open Access This article is distributed under the terms of the Creative Commons Attribution Noncommercial License which permits any noncommercial use, distribution, and reproduction in any medium, provided the original author(s) and source are credited.

\section{References}

Aoi S, Obara K, Hori S, Kasahara K, Okada Y (2001) New Japanese uphole/downhole strong-motion observation network: KiK-net. Seism Res Lett 72:239

Baba T (2002) Shape of subducting Philippine Sea plate. Chikyu 38:77-81 (in Japanese)

ERI database (2006) http://www-es.s.chiba-u.ac.jp/ satot/ ERIDB

Graves RW (1996) Simulating seismic wave propagation in 3D elastic media using staggered-grid finite differences. Bull Seism Soc Am 86:1091-1106

Hori T, Oike, K (1996) A statistical model of temporal variation of seismicity in the Inner Zone of Southwest Japan related to the great interplate earthquakes along the Nankai trough. J Phys Earth 44:349-356

Ito K (1999) Seismogenic layer, reflective lower crust, surface heat flow and large inland earthquakes. Tectonophysics 306:423-433

Ito $\mathrm{K}$, Sato $\mathrm{H}$, Hirose I, Umeda $\mathrm{Y}$, Hirata $\mathrm{N}$, Ito $\mathrm{T}$, Abe $\mathrm{S}$, Kawanaka T, Ikawa T (2005) Crust and upper mantle structure from seismic refraction and wide-angle reflection surveys and its relation to seismic activity in southwest Japan, AGU, Fall Meeting, T43A-1364

Iwata T, Kagawa T, Petukhin A, Onishi Y (2006) Basin and crustal structure model for strong motion simulation in Kinki, Japan, Proc. 3rd Int. Symp. Effect of Surface Geology on Seismic Motion, Grenoble, France, pp 435442

JAMSTEC database (2006) http://www.jamstec.go.jp/jamstec-j/ IFREE_center/

Kagawa T, Z̄hao B, Miyakoshi K, Irikura K (2004a) Modeling of $3 \mathrm{D}$ basin structures for seismic wave simulations based on available information on the target area: case study of the Osaka basin. Bull Seism Soc Am 94:1353-1368

Kagawa T, Iemura H, Irikura K, Toki K (2004b) Strong ground motion observation by the Committee of Earthquake Observation and Research in the Kansai Area (CEORKA). J Japan Assoc Earthq Eng 4(3), (Special Issue)

Kagawa T, Onishi Y, Cho I, Zhao B (2005) A technique to construct 3-D velocity structure model for strong ground motion evaluation, Proc. 3rd Symposium, Study on the Master Model for the Strong Motion Prediction toward Earthquake Disaster Mitigation, pp 83-86, (in Japanese with English abstract)

Kagawa T, Zhao B, Horie Y, Iwata T, Irikura K (2006) A study on construction and verification of $3-\mathrm{D}$ basin structure model for strong ground motion estimation in the Ohmi 
basin, Japan, Abstract of Fall meeting of the Seismological Society Japan, S116-P008 (in Japanese)

Kinoshita S (1998) Kyoshin Net (K-NET). Seism Res Lett 69:309-332

Kodaira S, Kurashimo, E, Park JO, Takahashi N, Nakanishi A, Miura, S, Iwasaki T, Hirata, N, Ito, K, Kaneda Y (2002) Structural factors controlling the rupture process of a megatrast earthquake at the Nankai trough seismogenic zone. Geophys J Int 149:815-835

Koketsu K, Higashi S (1992) Three dimensional topography of the sediment/basement interface in the Tokyo Metropolitan area, central Japan. Bull Seism Soc Am 82:2328-2349

Koketsu K, Hatayama K, Furumura T, Ikegami Y, Akiyama S (2005) Damaging long-period ground motions from the 2003 Mw 8.3 Tokachioki, Japan, earthquake. Seism Res Lett 76:67-73

Kyoto City (2004) 3rd earthquake damage estimation in Kyoto City, Kyoto City, p 236, (in Japanese)

Miyoshi T, Ishibashi K (2004) Geometry of the seismic Philippine Sea slab beneath the region from Ise Bay to Western Shikoku, Southwest Japan. Zisin 57:139-152 (in Japanese)

Nakanishi A, Shiobara, H, Hino R, Kodaira, S, Kanazawa, T, Shimamura H (1998) Detailed subduction structure across the eastern Nankai Trough obtained from ocean bottom seismographic profiles. J Geophys Res 103:27151-27168

Nakanishi A, Takahashi N, Park JO, Miura S, Kodaira S, Kaneda Y, Hirata N, Iwasaki T, Nakamura M (2002) Crustal structure across the coseismic rupture zone of the 1944 Tonankai earthquake, the central Nankai Trough seismogenic zone. J Geophys Res 107 DOI 10.1029/ 2001JB000424

Petukhin A, Irikura K, Ohmi S, Kagawa T (2003) Estimation of Q-values in the seismogenic and aseismic layers in the Kinki region, Japan, by elimination of the geometrical spreading effect using ray approximation. Bull Seism Soc Am 93:1498-1515
Petukhin A, Iwata T, Kagawa T (2007) Study of the effect of the oceanic water layer on the strong ground motion simulation. Japan Geoscience Union meeting S145-P013

Pitarka A (1999) 3D elastic finite-difference modeling of seismic motion using staggered grids with nonuniform spacing. Bull Seism Soc Am 89:54-68

Salah M, Zhao D (2003a) 3-D seismic structure of Kii Peninsula in Southwest Japan: Evidence for slab dehydration in the forearc. Tectonophysics 364:191-213

Salah M, Zhao D (2003b) Three-dimensional attenuation structure of Southwest Japan estimated from spectra of microearthquakes. Phys Earth Planet Inter 13G:215231

Salah M, Zhao, D (2004) Mapping the crustal thickness in Southwest Japan using Moho reflected waves. Phys Earth Planet Int 141:79-94

Shiomi K, Obara K, Sato H (2004a) Moho depth variation beneath Chugoku-Shikoku region, the Seismological Society of Japan, 2004 Fall Meeting, B059 (in Japanese)

Shiomi K, Sato H, Obara K, Ohtake M (2004b) Configuration of subducting Philippine Sea plate beneath southwest Japan revealed from receiver function analysis based on the multivariate autoregressive model. J Geophys Res DOI 10.1029/2003JB002774

The Headquarters for Earthquake Research Promotion (2007) http://www.jishin.go.jp/main/index-e.html

Wassel P, Smith WHF (1998) New, improved version of the Generic Mapping Tools released. EOS Trans Am Geophys Union 79:579

Yamada N, Iwata T (2005) Long-period ground motion simulation in the Kinki area during the $\mathrm{M}_{\mathrm{J}} 7.1$ foreshock of the 2004 off the Kii peninsula earthquakes. Earth Planets Space 57:197-202

Yamauchi M, Hirahara K, Shibutani T (2003) High resolution receiver function imaging of the seismic velocity discontinuities in the crust and the uppermost mantle beneath Southwest Japan. Earth Planets Space 55:59-64 